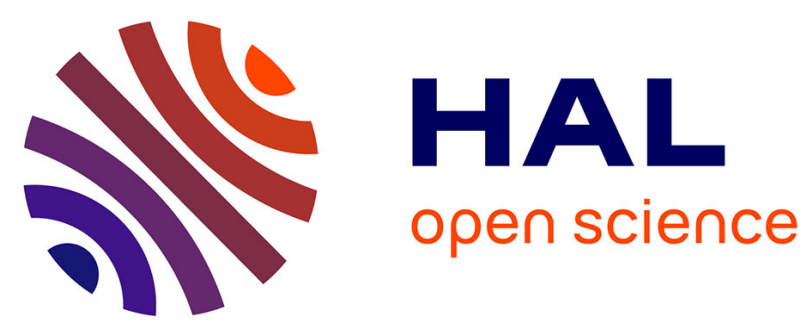

\title{
Multi axis representation and Euclidean distance of muscle fatigue indexes during evoked contractions
}

\author{
Maxime Yochum, Toufik Bakir, Stéphane Binczak, Romuald Lepers
}

\section{To cite this version:}

Maxime Yochum, Toufik Bakir, Stéphane Binczak, Romuald Lepers. Multi axis representation and Euclidean distance of muscle fatigue indexes during evoked contractions. 2014 IEEE Region 10 Symposium, Apr 2014, Kuala Lumpur, Malaysia. 10.1109/TENCONSpring.2014.6863074 . hal-01328485

\section{HAL Id: hal-01328485 \\ https://hal.science/hal-01328485}

Submitted on 8 Jun 2016

HAL is a multi-disciplinary open access archive for the deposit and dissemination of scientific research documents, whether they are published or not. The documents may come from teaching and research institutions in France or abroad, or from public or private research centers.
L'archive ouverte pluridisciplinaire HAL, est destinée au dépôt et à la diffusion de documents scientifiques de niveau recherche, publiés ou non, émanant des établissements d'enseignement et de recherche français ou étrangers, des laboratoires publics ou privés. 


\section{Multi Axis Representation and Euclidean Distance of Muscle Fatigue indexes During Evoked Contractions}

\author{
Maxime Yochum, Toufik Bakir, Stéphane Binczak \\ LE2I UMR CNRS 6306 \\ University of Burgundy \\ 9 avenue Alain Savary \\ 21078 Dijon, France \\ stbinc@u-bourgogne.fr
}

\author{
Romuald Lepers \\ Laboratory INSERM U1093 \\ University of Burgundy \\ BP27877 \\ 21078 Dijon, France \\ romuald.lepers@u-bourgogne.fr
}

\begin{abstract}
In this article, we proposed a new representation of muscular fatigue during evoked muscle contractions based on fatigue indexes such as peak to peak amplitude, RMS of the $M$ wave, mean and median frequency and fatigue index calculated from continuous wavelet transform ( $\left.\mathbf{I}_{\mathrm{CWT}}\right)$. These new representations of muscle fatigue using multi axis represented and Euclidean distance give better insights on changes in physiological characteristics during muscle fatigue. This technique provides a fatigue index using several muscle characteristics. The use of other kinds of fatigue characteristics as force could also be possible.
\end{abstract}

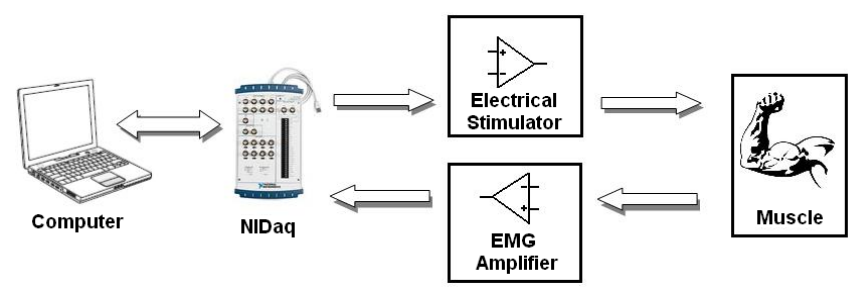

Fig. 1. General diagram of the system

\section{MATERIAL}

\section{INTRODUCTION}

Since several decades, researchers try to understand characteristic changes of muscles during contractions. Those muscles characteristics are used to diagnosis muscle diseases [1], [2]. They are also very important to characterize muscles of paralyzed patients because these patients are not able to have feelings about their muscles [3]. The most common device to acquire information of muscles is the electromyogram (EMG) [4]. EMG represents electrical muscular activity of muscular fibers around electrodes. Those electrical activities are recorded during voluntary or electrical evoked muscle contractions. In a present study, we characterized muscular fatigue during evoked contractions using EMG signal with fatigue indexes such as the peak to peak (PTP), the root mean square (RMS), the mean $\left(\mathrm{F}_{\text {mean }}\right)$ and the median frequency $\left(\mathrm{F}_{\mathrm{med}}\right)$. Those indexes are valid for fatigue characterisation during evoked muscle contractions by electromyostimulation [5]. In previous studies [6] [7], we proposed a new fatigue index based on wavelet computation named $I_{C W T}$. Fatigue indexes are computed in real time during evoked contractions by an electrical stimulator with constant current pulses. The purposes of this study are i) to present a multi-axis visualization of several fatigue indexes and ii) to present a new fatigue index dependent of several physiological characteristics existing in fatigue indexes [5], [8] using Euclidean distance. In that way, the fatigue index depends on several $\mathrm{M}$ wave aspects rather than just a single one. In addition, we plot fatigue indexes during several consecutive electrical stimulations (such as in a real electrical stimulation pattern for rehabilitation) showing differences in physiological changes in muscle over stimulations.

\section{A. The Device}

The material of our experiment allows the electrical stimulation and the acquisition of EMG in real time [6] [7]. A diagram of its constitution is shown in Fig. 1. The electrical stimulator generates controlled current pulses and delivers constant stimulation over time to different muscles. It delivers a maximum intensity of $100 \mathrm{~mA}$ for a body impedance of $1.5 \mathrm{k} \Omega$ between the two stimulation electrodes, a frequency pulse train from $10 \mathrm{~Hz}$ to $100 \mathrm{~Hz}$ and a pulse time from $0.5 \mathrm{~ms}$ to $2 \mathrm{~ms}$ for 5 different kinds of pulse shapes shown in Fig. 2A which are the most common in literature. The EMG amplifier acquires EMG from muscle during the stimulation with bipolar electrodes and a reference electrode. Amplifiers used for this circuit are $I N A 128$ from Texas Instruments with a $120 d B$ of Common Mode Rejection Ratio (CMRR) for a good removal of common voltage on bipolar electrodes. The $M$ waves are extracted from EMG signal during evoked contractions. A software manages stimulation parameters and analyzes the fatigue indexes with the algorithms present in the next section. A screenshot of the software interface is shown in Fig. 2B.

\section{B. The Fatigue Indexes}

Fatigue indexes are computed for each $\mathrm{M}$ wave during a stimulation train. The amplitude of $\mathrm{M}$ waves is named $\mathrm{V}_{\mathrm{EMG}}$. The fatigue index based on CWT $\left(\mathrm{I}_{\mathrm{CWT}}\right)$ from our previous work [6] [7] gives an estimation of the dilation undergoing by $\mathrm{M}$ waves during an electrical stimulation. $\mathrm{I}_{\mathrm{CWT}}$ is computed 


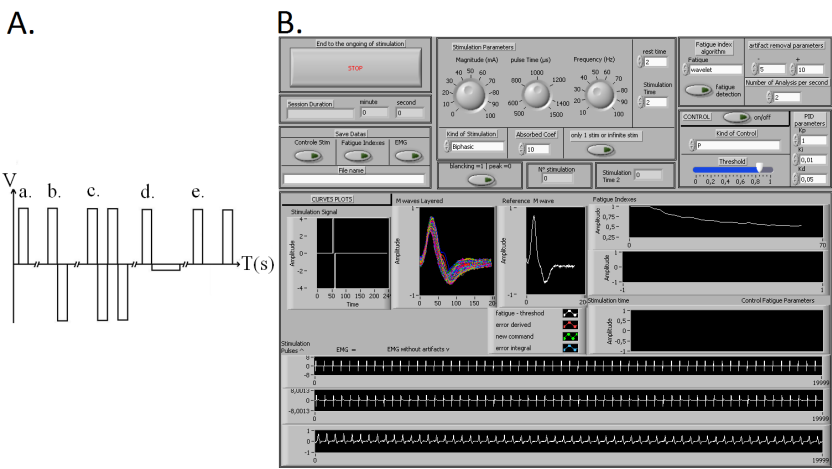

Fig. 2. A: Waveforms that can be sent to the stimulation board. a. Monophasic. b. Biphasic. c. Dual Biphasic. d. Absorbed Biphasic, the magnitude of negative phase depends on an absorbed coefficient percentage. Positive and negative surface are equal. e. doublet Nlet [9]. B: Software interface.

according to the following equation:

$$
C_{a, b}\left(V_{E M G}(t), \hat{\psi}(t)\right)=\int_{-\infty}^{\infty} V_{E M G}(t) \frac{1}{\sqrt{a}} \hat{\psi}\left(\frac{t-b}{a}\right) d t,
$$

where $\hat{\psi}$ is an estimated wavelet from the first $\mathrm{M}$ wave of the stimulation, $a$ is a scale factor (temporal dilation) and $b$ indicates the temporal location. Then $a$ are taken for the corresponding $C_{a, b}$ local maximum values. The $a$ represents the dilation of $\mathrm{M}$ wave over time. This fatigue index tends to increase over time while the traditional fatigue indexes from literature such as peak to peak amplitude of the $\mathrm{M}$ wave and RMS tend to decrease. Therefore the retained scale factor $a$ is putted to the power of minus one to keep the tendency of the other indexes. The equation is then:

$$
I_{C W T}=\left[\underset{a}{\operatorname{argmax}}\left\{C_{a, b}(s(t), \hat{\psi}(t))\right\}\right]^{-1} .
$$

Four different fatigue indexes from literature [5], [8], [10], [11], [12], [13] have been implemented for this study. They all represent a characteristic of $\mathrm{M}$ wave over an electrical stimulation. The PTP is the amplitude of the $\mathrm{M}$ wave. The PTP values are computed as:

$$
P T P=\max \left(V_{E M G}\right)-\min \left(V_{E M G}\right) .
$$

The RMS value is the area of the M wave.

$$
R M S=\sqrt{\sum_{i=0}^{n} V_{E M G}(i)^{2}} .
$$

The two last fatigue indexes are in the frequency domain. The first one is the mean frequency which is an average of the total power spectrum, computed as:

$$
F_{\text {mean }}=\frac{\sum_{i=0}^{n} P S D_{i} \cdot f_{i}}{\sum_{i=0}^{n} P S D_{i}},
$$

where $P S D$ is the power spectrum density of $\mathrm{V}_{\mathrm{EMG}}$ and $f$ the frequency vector. The second one is the median frequency; it is the frequency which separates the total spectrum density in two identical parts.

$$
\sum_{i=0}^{F_{\text {med }}} P S D_{i}=\sum_{i=F_{\text {med }}}^{n} P S D_{i}=\frac{1}{2} \cdot T S D
$$

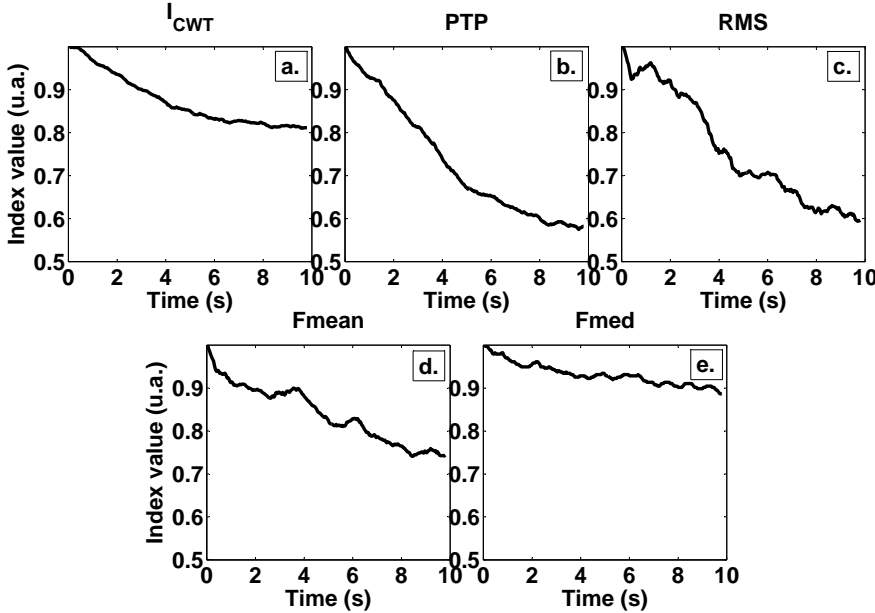

Fig. 3. Examples of fatigue indexes: a. CWT based $\left(\mathrm{I}_{\mathrm{CWT}}\right)$, b. Peak to Peak $(\mathrm{PTP})$, c. Root Mean Square (RMS), d. Mean Frequency $\left(\mathrm{F}_{\text {mean }}\right)$, e. Median Frequency $\left(\mathrm{F}_{\mathrm{med}}\right)$.

where $T S D$ is the total spectrum density.

All previous fatigue indexes are normalized between 0 and 1 , where 1 corresponds to the maximum value of the fatigue index, during a unique stimulation or a series of stimulations. The normalized fatigue indexes are as:

$$
n F_{\text {index }}=\frac{F_{\text {index }}}{\max \left(F_{\text {index }}\right)},
$$

where $F_{\text {index }}$ is the fatigue index among $\mathrm{I}_{\mathrm{CWT}}$, PTP, RMS, $F_{\text {mean }}$ and $F_{\text {med }}$. The Fig. 3 gives an example of the changes of the different fatigue indexes during an evoked contraction. We note that all fatigue indexes vary over a contraction performed electrically. They vary from one at the beginning of the stimulation session to lower values depending on the muscular fatigue. Those changes are the representation of physiological changes inside the muscle fibers [5], [8].

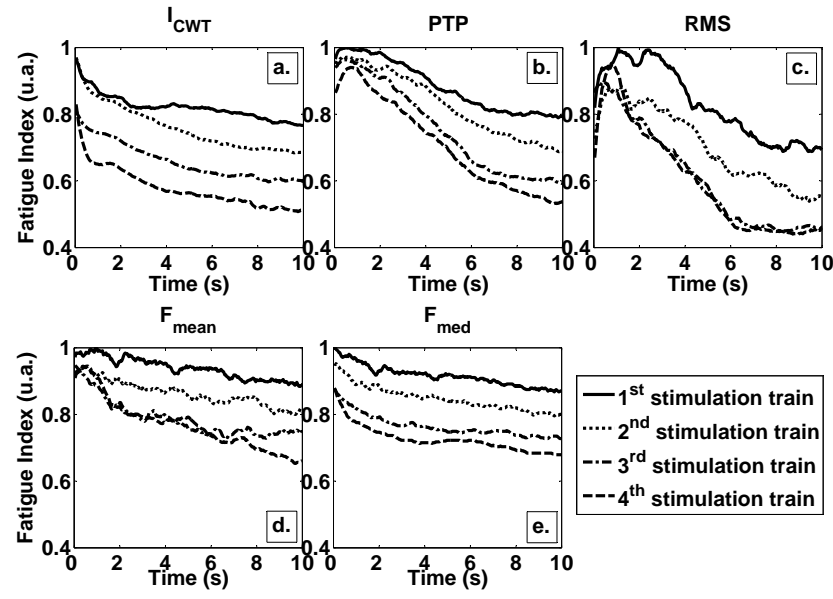

Fig. 4. Examples of fatigue indexes for 4 consecutive contractions with $10 \mathrm{~s}$ of stimulation and $10 s$ of rest: a. $\mathrm{I}_{\mathrm{CWT}}$, b. PTP, c. RMS, d. $\mathrm{F}_{\text {mean }}$, e. $\mathrm{F}_{\text {med }}$. 

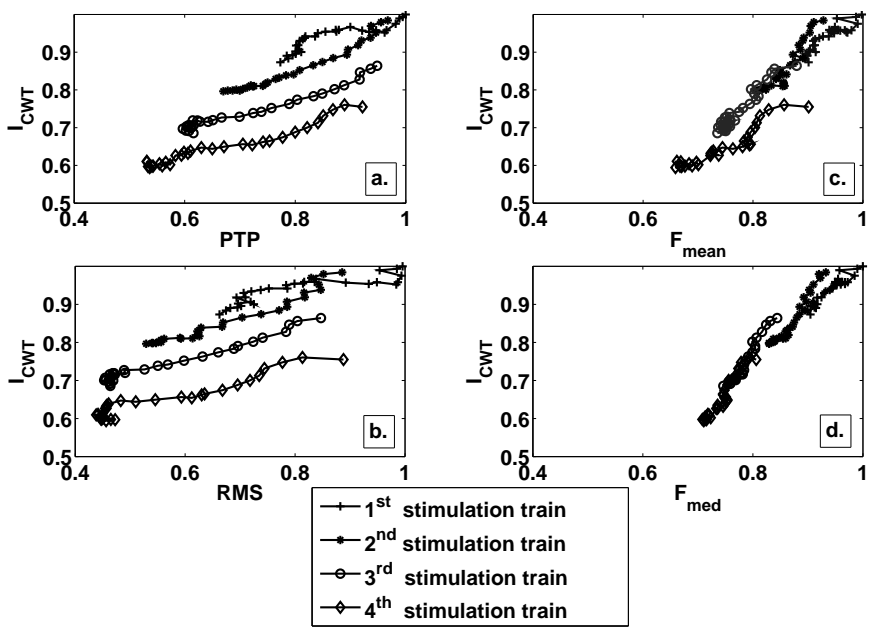

Fig. 5. Examples of XY curves with: a. $\mathrm{I}_{\mathrm{CWT}}$ and PTP, b. $\mathrm{I}_{\mathrm{CWT}}$ and RMS, c. $\mathrm{I}_{\mathrm{CWT}}$ and $\mathrm{F}_{\text {mean }}, \mathrm{d}$. $\mathrm{I}_{\mathrm{CWT}}$ and $\mathrm{F}_{\text {med }}$.

\section{Method}

The stimulations have been made on the biceps brachia. The electrical parameters have been fixed for five male subjects aged from 24 to 28 . Those stimulation parameters were a $50 \mathrm{~mA}$ current amplitude, a $1 \mathrm{~ms}$ pulse duration, a $30 \mathrm{~Hz}$ frequency and a biphasic pulse shape (see Fig. 2.I,b). The 5 fatigue quantification algorithms have been performed for each stimulation. In the Fig. 4, fatigue indexes have been plotted for 4 consecutive $10 s$ stimulations with a rest time between two stimulations of $10 \mathrm{~s}$. For the five fatigue indexes, the fatigue becomes more and more important over the stimulations trains. The fatigue index based on CWT follows the same tendency than the others. This findings suggested that muscle did not recover during the $10 s$ of granted rest.

\section{COMMON FATIGUE INDEX}

\section{A. Two axis representation}

In order to have a representation of several physiological fatigue characteristics of the fatigue indexes among the $\mathrm{I}_{\mathrm{CWT}}$ and the others fatigue indexes (PTP, RMS, $F_{\text {mean }}$ and $F_{\text {med }}$ ), XY displays have been plotted in Fig. 5. The $\mathrm{Y}$ axes are the $\mathrm{I}_{\mathrm{CWT}}$ indexes and the $\mathrm{X}$ axes are the common fatigue indexes. This representation shows the differences between coupled indexes. For instance, the panel a in Fig. 5 ( $\mathrm{I}_{\mathrm{CWT}}$ with PTP) shows that the result for each stimulation train is different. For the $1^{\text {st }}$ stimulation train, points are more grouped and close to the coordinate [1 1 ] while for the $4^{t h}$ stimulation train the results are more extent and more away from the coordinate [1 1]. This can be interpreted as a sign of an increase of muscle fatigue. Considering two fatigue indexes instead of one could reinforce the characterization of the muscle fatigue by taking several physiological information such as amplitude, shape and frequency aspects of $\mathrm{M}$ waves which correspond to recruited muscle fiber number or action potential velocity for example.

\section{B. Three axis representation}

The graphics in Fig. 6 correspond to 3D representation of 3 fatigue indexes. Taking one more dimension consolidates the previous determinations. Graphics show that the results

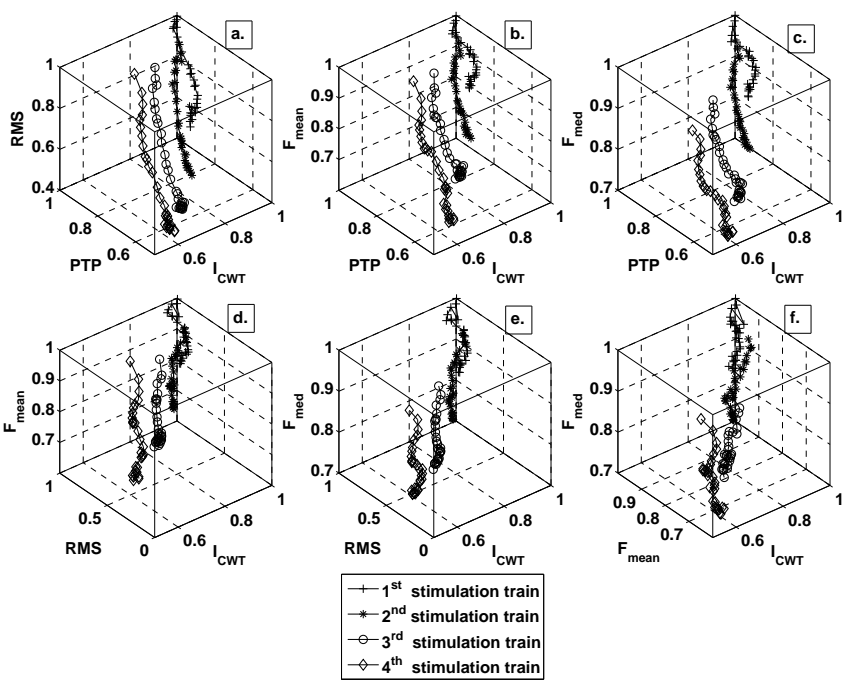

Fig. 6. Examples of XYZ 3D curves with: a. $\mathrm{I}_{\mathrm{CWT}}$ and PTP and RMS, b $\mathrm{I}_{\mathrm{CWT}}$ and PTP and $\mathrm{F}_{\text {mean }}, \mathrm{c}$. $\mathrm{I}_{\mathrm{CWT}}$ and PTP and and $\mathrm{F}_{\text {med }}, \mathrm{d}$. $\mathrm{I}_{\mathrm{CWT}}$ and RMS and $F_{\text {mean }}$, e. $I_{C W T}$ and RMS and $F_{\text {med }}$, f. $I_{C W T}$ and $F_{\text {mean }}$ and $F_{\text {med }}$

for different stimulation trains take different ways suggesting that muscular fatigue behavior differs over several consecutive electrical contractions.

\section{Euclidean distance}

The 3D representations allow to visualize changes of several fatigue indexes in the same time but they do not give a mathematical indicator of those changes. In addition, when the dimension is 4 or more, their visualizations become very difficult. Thus, we chose the computation of the Euclidean distance $(E D)$ as a common fatigue index. The $E D$ is computed between the coordinate for a non fatigued muscle which are 1 for all dimensions and the results of fatigue indexes over stimulations. The Euclidean distance is computed as:

$$
E D(i)=\sqrt{\sum_{n=1}^{N}\left(1-F_{n}(i)\right)^{2}},
$$

where $E D$ is the Euclidean distance, $\mathrm{N}$ is the number of dimensions and $F_{n}$ the fatigue index chosen according to the dimension. For a 3D representation, 3 fatigue algorithms have been chosen, therefore $N=3$ and then:

$$
E D(i)=\sqrt{\left[1-F_{1}(i)\right]^{2}+\left[1-F_{2}(i)\right]^{2}+\left[1-F_{3}(i)\right]^{2}},
$$

where $F_{1}(i), F_{2}(i)$ and $F_{3}(i)$ are three different fatigue indexes chosen (among $\mathrm{I}_{\mathrm{CWT}}$, PTP, RMS, $\mathrm{F}_{\text {mean }}$ and $\mathrm{F}_{\mathrm{med}}$ ). An example of $E D$ is shown in Fig. 7. As $E D$ is dependent of three fatigue algorithms, it represents the fatigue of three physiological muscle parameters. If we consider the panel a in Fig. 7, the $E D$ is dependent of $\mathbf{M}$ wave shapes $\left(\mathrm{I}_{\mathrm{CWT}}\right), \mathbf{M}$ wave amplitudes (PTP) and $\mathrm{M}$ wave frequencies $\left(\mathrm{F}_{\text {mean }}\right) . E D$ is normalized between 0 and 1 where 1 is a $E D=0$ and 0 is the maximal length of the $E D$. According to the equation 8, the maximal length of $E D$ depends of the number of dimension. The maximal length of each dimension is for $F_{n}(i)=0$. Therefore:

$$
E D(\max )=\sqrt{\sum_{n=1}^{N}(1-0)^{2}}=\sqrt{N},
$$



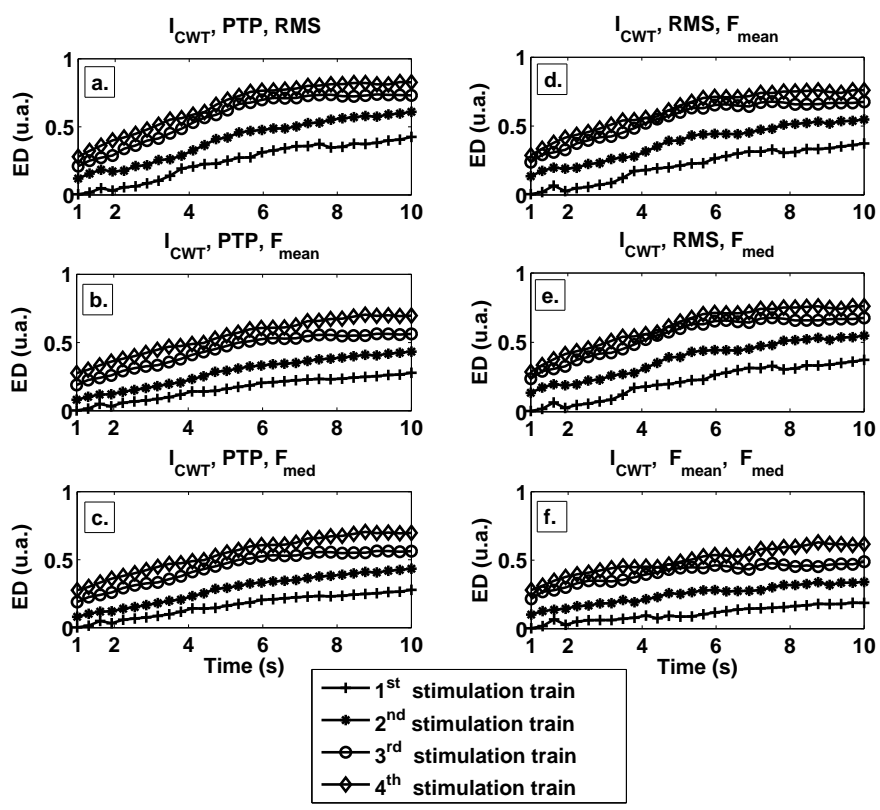

Fig. 7. Examples of Euclidean distance $(E D)$ for different combinations of fatigue algorithm: a. $\mathrm{I}_{\mathrm{CWT}}$ and PTP and RMS, b. $\mathrm{I}_{\mathrm{CWT}}$ and PTP and $\mathrm{F}_{\text {mean }}, \mathrm{c}$. $\mathrm{I}_{\mathrm{CWT}}$ and PTP and and $\mathrm{F}_{\text {med }}, \mathrm{d}$. $\mathrm{I}_{\mathrm{CWT}}$ and RMS and $\mathrm{F}_{\text {mean }}$, e. $\mathrm{I}_{\mathrm{CWT}}$ and RMS and $F_{\text {med }}, f$. $I_{C W T}$ and $F_{\text {mean }}$ and $F_{\text {med }}$

and, the normalized $E D$ equation is as:

$$
n E D(i)=1-\frac{E D(i)}{E D_{\max }},
$$

The normalization maintains the result between 0 and 1 whatever the number of dimensions and keeps the tendency of others fatigue indexes which decreases during an electrical stimulation. Examples of normalized $E D$ corresponding to the graphic a in Fig. 7 with $\mathrm{I}_{\mathrm{CWT}}$, PTP and RMS fatigue indexes for 4 consecutive stimulations are shown in Fig. 8 .

\section{DISCUSSION \& CONCLUSION}

This study examined 5 fatigue indexes computed from $M$ waves inside EMG recorded during electrical stimulations: the peak to peak, the root mean square, the mean frequency, the median frequency and one based on the continuous wavelet transform. This study proposed a multi axis representation of fatigue indexes. Then, this representation was used to find a new fatigue index based on several standard fatigue indexes and the Euclidean distance algorithm. In this study, 5 fatigue indexes are used but the computation of common fatigue index is not limited in the number of fatigue indexes used or their issue as long as they are normalized. For instance, PTP duration instead of PTP amplitude or the use of a force measurement instead of EMG features. The common fatigue index is normalized between [0 1] and tends to decrease as the standard fatigue indexes from literature. The interest of this new representation is the use of several physiological characteristics of muscle fibers into a unique index. The use of $\mathrm{I}_{\mathrm{CWT}}$, PTP and $\mathrm{F}_{\text {mean }}$ provides information about shapes, amplitudes and frequencies aspects grouped into an index. It could also grouped other kinds of muscular characteristic as force, torque or oxygen intake for example. A statistical study remains to be done to compare this common fatigue index

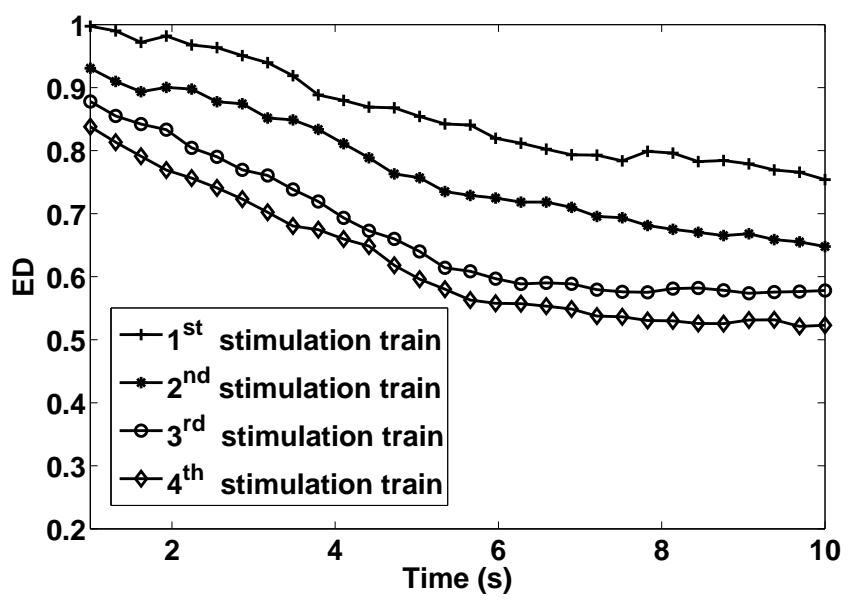

Fig. 8. Example of Euclidean distance $(E D)$ normalized corresponding to the graphic a in Fig7 with $\mathrm{I}_{\mathrm{CWT}}$, PTP and RMS for 4 consecutive stimulation

with the standard ones and correlate them with physiological aspects. Investigate the possible merging of different kinds of muscular features like strength and EMG could also be an interesting study.

\section{REFERENCES}

[1] A. Labarre-Vila, "Electromyographie de surface et fonction musculaire en pathologie," Revue Neurologique, vol. 162, no. 4, pp. 459-465, 2006.

[2] M. Zwarts, G. Drost, and D. Stegeman, "Recent progress in the diagnostic use of surface EMG for neurological diseases," Journal of Electromyography and Kinesiology, vol. 10, no. 5, pp. 287-291, 2000.

[3] J. Mizrahi, M. Levy, H. Ring, E. Isakov, and A. Liberson, "EMG as an indicator of fatigue in isometrically FES-activated paralyzed muscles," Rehabilitation Engineering, IEEE Transactions on, vol. 2, no. 2, pp. 5765, 1994.

[4] P. Konrad, "The abc of emg," A Practical Introduction to Kinesiological Electromyography, vol. 1, 2005.

[5] J. Mizrahi, "Fatigue in muscles activated by functional electrical stimulation," Critical Reviews in Physical and Rehabilitation Medicine, vol. 9, no. 2, 1997.

[6] M. Yochum, T. Bakir, R. Lepers, and S. Binczak, "Estimation of muscular fatigue under electromyostimulation using cwt," IEEE transaction on Biomedical Engineering, vol. 59, no. 12, pp. 3372 - 3378, 2012.

[7] M. Yochum, T. Bakir, R. Lepers, and S. Binczak, "A real time electromyostimulator linked with emg analysis device," IRBM, vol. 34, no. 1, pp. 43-47, 2013.

[8] N. Dimitrova, J. Hogrel, T. Arabadzhiev, and G. Dimitrov, "Estimate of M-wave changes in human biceps brachii during continuous stimulation," Journal of Electromyography and Kinesiology, vol. 15, no. 4, pp. 341-348, 2005.

[9] Z. Karu, W. Durfee, and A. Barzilai, "Reducing muscle fatigue in FES applications by stimulating with N-let pulse trains," Biomedical Engineering, IEEE Transactions on, vol. 42, no. 8, pp. 809-817, 1995.

[10] J. Mizrahi, O. Levin, A. Aviram, E. Isakov, and Z. Susak, "Muscle fatigue in interrupted stimulation: effect of partial recovery on force and EMG dynamics," Journal of Electromyography and Kinesiology, vol. 7, no. 1, pp. 51-65, 1997.

[11] D. Tepavac and L. Schwirtlich, "Detection and prediction of FESinduced fatigue," Journal of Electromyography and Kinesiology, vol. 7, no. 1 , pp. 39-50, 1997.

[12] N. Chesler and W. Durfee, "Surface EMG as a fatigue indicator during FES-induced isometric muscle contractions," Journal of Electromyography and Kinesiology, vol. 7, no. 1, pp. 27-37, 1997.

[13] C. Thomas, "Fatigue in human thenar muscles paralysed by spinal cord injury," Journal of Electromyography and Kinesiology, vol. 7, no. 1, pp. 15-26, 1997. 